\title{
Research on Evaluation of Input and Output of Physical Assets of Power Grid Enterprises Based on DEA Theory
}

\author{
Fuyan Liu ${ }^{1}$, Min $\mathrm{Yu}^{2}$, Xiaohui $\mathrm{Li}^{3}$, Jinpeng Liu ${ }^{4, *}$ Xiaoyan $\mathrm{Yu}^{5}$ \\ ${ }^{1}$ Economic and Technological Research Institute, State Grid Zhejiang Power Co., Ltd. Hangzhou, China \\ ${ }^{2}$ Economic and Technological Research Institute, State Grid Zhejiang Power Co., Ltd. Hangzhou, China \\ ${ }^{3}$ State Grid Zhejiang Power Co., Ltd. Comprehensive Service Branch Hangzhou, China \\ ${ }^{4}$ School of Economics and Management, North China Electric Power University Beijing, China. \\ ${ }^{5}$ Economic and Technological Research Institute, State Grid Zhejiang Power Co., Ltd. Hangzhou, China
}

\begin{abstract}
With the continuous and rapid development of the national economy and the improvement of people's living standards, the construction of regional power grids is gradually increasing, and the corresponding investment will also increase. If the scale of investment is too small or lagging, it will inevitably fail to meet the requirements of economic and social development and load growth. It will also affect the long-term development of the enterprise and fail to achieve the expected investment benefits. However, if the scale of investment is too large or too advanced, it will inevitably cause waste of funds and excess resources, and will also cause business pressure. Therefore, it is necessary to carry out input-output efficiency evaluation research on regional power grids to determine whether the scale of power grid construction is appropriate and whether the input and output match. Therefore, this paper uses the DEA input-output theory, combined with the analysis of the actual asset investment objectives of power grid companies, to build a comprehensive input-output evaluation system, and optimally conduct empirical analysis based on the actual data of various units in a certain area, which can provide support and guide.
\end{abstract}

\section{INTRODUCTION}

Under the new situation, the reasonable scale of investment in power grid physical assets has an important impact on the production, operation and business development of enterprises. Improving quality and efficiency has become an important means for power grid companies to enhance their core competitiveness and ensure the steady improvement of business efficiency.

Literature [1] proposes the calculation method of "cost index" and "benefit index" of distribution network engineering project based on "asset full life cycle" and "relevant grid", and constructs the economic evaluation model of project feasibility study. Literature [2] finds out the outstanding problems in the development of distribution network through the current grid development level and input-output evaluation analysis. This paper Combining with the needs of future power grid development scale, establish a comprehensive decisionmaking method for investment strategy considering the matching degree and equilibrium degree of distribution network development. Eventually achieve precise investment goals.

Literature [3] uses the power grid enterprise distribution network investment management system and development strategy goals as the outline, sorts out the key input resources and output data of the distribution network by voltage level, and uses the key success factor decomposition method to distinguish the key input indicators and key outputs Class indicators, clarify the design ideas of the input and output efficiency indicators of the distribution network. Literature [4] proposes a power grid investment efficiency benefit evaluation index system for incremental input, stock input, and output efficiency benefits, and K-means clustering to improve the efficiency evaluation method of data envelopment analysis, based on the sensitivity analysis of index efficiency to obtain subsequent investment pending The direction of improvement. In reference to the different problems that need to be solved in power grid planning investment, literature [5] formulates typical power grid planning investment scenarios, which are divided into rigid demand scenarios and flexible demand scenarios, and comprehensively consider the input-output benefits of different scenarios, and establish power grid planning Comprehensive evaluation index system and evaluation method for input-output benefits of the whole life cycle.

In summary, based on the analysis of the current situation of the physical asset input of power grid companies, this paper carries out input and output evaluation, which is important for strengthening the guidance of regional power grid construction, realizing precise investment in power grid, promoting the scientific, reasonable and orderly development of power grid, and 
improving power grid development capacity and enterprise development benefits significance.

\section{THE BASIC PRINCIPLES OF INPUT-OUTPUT EVALUATION BASED ON DEA THEORY}

The data envelopment analysis method (abbreviated as DEA method) is a linear programming model, a representative of non-parametric methods, expressed as the ratio of output to input. By comparing the efficiency of a specific unit with the performance of a group of similar units providing the same service, the efficiency of the service unit can be maximized. It is mainly suitable for evaluating the relative effectiveness of decision-making units with multiple inputs and multiple outputs.

Its economic significance is: if a decision-making unit is DEA effective, from the perspective of the production function, it is both technically effective and scale-effective, that is to say, for these decision-making units, the input and output obtained have been Reach the best.

\section{CONSTRUCTION OF INPUT-OUTPUT EVALUATION INDEX SYSTEM}

\subsection{Principles of index system construction}

Establishing and improving the quality evaluation index system is of great practical significance for improving the quality of evaluation work. Through many practical studies, it is known that the selection of indicators will seriously affect the evaluation results. From this point of view, the establishment of the indicator system requires a clear purpose and principles. How to choose indicators is a question that requires careful consideration. When selecting indicators, usually the following basic principles should be adhered to: Comprehensive principle, Principle of Comparability, Materiality principle, Irrelevant principle, The principle of operability.

When constructing the index system, it is far from enough to simply rely on the simple accumulation of each index. While being representative, it must be ensured that it is comprehensive, and the content of the evaluated object must be displayed as comprehensively as possible., To be able to study the evaluation object from an all-round and three-dimensional perspective.

There are many indicators involved in the indicator system. In this case, it is necessary to maintain consistency as much as possible in terms of indicator calculation time, calculation caliber, measurement unit, etc., so as to make later comparisons simple and convenient.

The choice of indicators should have a reasonable range, too much or too little is not appropriate. While ensuring that it abides by the principle of comprehensiveness, it should also reflect the difference between primary and secondary, and consider all aspects in place. Otherwise, it will easily lead to the entire system without a central point, unclear routes, and lack of organization, which is detrimental to the solution of the problem. .

Each indicator in the indicator system should be concise and clear. Indicators at the same level should avoid duplication of content as much as possible. If there is a linear functional relationship between output indicators and input indicators, it will appear in the DEA model that the decision-making units are relatively effective. Therefore, it is necessary to ensure that the various indicators are irrelevant.

When selecting the index system, the simplicity of collecting data, easy operation, and accuracy of data should be considered. It is necessary to ensure that the obtained indicator data is scientific, reasonable, true and effective.

\subsection{Construction of input-output evaluation index system}

Through investigating the investment in regional power grid construction; at the same time, based on the research content of domestic and foreign literature and the opinions of relevant experts, combined with the "universal applicability principle" and the "accessibility principle", the final selection includes total assets and fixed asset investment Input indicators that fully describe the investment status, such as volume, capacity-to-load ratio, GDP growth rate, line loss rate, etc., according to the economic efficiency of various investments as the target value, and directly measure the economic efficiency of the unit asset increase power supply indicator as the output index. The details are as follows:

TABLE I. DEA EVALUATION INDEX SYSTEM FOR FIXED ASSET INVESTMENT

\begin{tabular}{|l|l|}
\hline \multicolumn{1}{|c|}{ Index category } & \multicolumn{1}{c|}{ Index } \\
\hline \multirow{4}{*}{ Enter index } & Total assets \\
\cline { 2 - 2 } & Fixed asset investment \\
\cline { 2 - 2 } & Capacity ratio \\
\cline { 2 - 2 } & Line loss rate \\
\cline { 2 - 2 } & \\
\hline Output index & Increased power supply per unit investment \\
\hline
\end{tabular}




\section{EMPIRICAL ANALYSIS}

company in each region for analysis, as shown in the table below.

Now select the indicator data of a provincial power grid

TABLE II. 2018-2019 INPUT-OUTPUT INDICATOR DATA TABLE OF EACH REGION

\begin{tabular}{|c|c|c|c|c|c|c|c|}
\hline Year & DMU & $\begin{array}{l}\text { (I)Total assets }(100 \\
\text { million yuan) }\end{array}$ & $\begin{array}{l}\text { (I)Fixed asset investment } \\
\text { (10 thousand yuan) }\end{array}$ & $\begin{array}{l}\text { (I)Capacity } \\
\text { ratio }\end{array}$ & $\underset{\text { rate }}{\text { (I)Line loss }}$ & $\begin{array}{l}\text { (I)GDP growth } \\
\text { rate }(\%)\end{array}$ & $\begin{array}{l}\text { (O)Unit investment to increase } \\
\text { power supply the amount }\end{array}$ \\
\hline \multirow{11}{*}{2018} & A & 115.89 & 187093.68 & 2.25 & 3.23 & 10.47 & 1.85 \\
\hline & B & 65.18 & 103014.20 & 2.12 & 3.57 & 7.83 & 1.89 \\
\hline & $\mathrm{C}$ & 79.86 & 136303.21 & 1.87 & 3.44 & 7.62 & 2.51 \\
\hline & $\mathrm{D}$ & 26.72 & 40819.43 & 2.31 & 3.70 & 6.3 & 0.45 \\
\hline & $\mathrm{E}$ & 75.52 & 112327.75 & 2.22 & 4.76 & 7.26 & 1.23 \\
\hline & $\mathrm{F}$ & 63.69 & 89224.53 & 2.09 & 2.78 & 6.89 & 2.09 \\
\hline & G & 27.32 & 44839.31 & 1.9 & 3.70 & 7.98 & 2.58 \\
\hline & $\mathrm{H}$ & 36.96 & 78269.03 & 2.88 & 5.56 & 7.49 & 1.17 \\
\hline & I & 44.39 & 69041.70 & 2.27 & 2.78 & 7.07 & 1.81 \\
\hline & $\mathrm{J}$ & 61.29 & 95418.79 & 2.07 & 5 & 7.29 & 2.51 \\
\hline & $\mathrm{K}$ & 10.32 & 7935.56 & 3.24 & 5 & 6.32 & 0.82 \\
\hline \multirow{11}{*}{2019} & $\mathrm{~A}$ & 123.96 & 200107.68 & 2.41 & 3.03 & 11.2 & 1.98 \\
\hline & B & 68.35 & 108020.95 & 2.22 & 3.45 & 8.21 & 1.98 \\
\hline & $\mathrm{C}$ & 86.79 & 148138.89 & 2.03 & 3.13 & 8.28 & 2.73 \\
\hline & $\mathrm{D}$ & 28.44 & 43444.97 & 2.46 & 3.45 & 6.7 & 0.48 \\
\hline & $\mathrm{E}$ & 78.03 & 116059.04 & 2.29 & 4.55 & 7.5 & 1.27 \\
\hline & $\mathrm{F}$ & 65.79 & 92170.08 & 2.16 & 2.7 & 7.12 & 2.16 \\
\hline & G & 28.55 & 46860.17 & 1.99 & 3.57 & 8.34 & 2.7 \\
\hline & $\mathrm{H}$ & 38.46 & 81444.09 & 3 & 5.26 & 7.79 & 1.22 \\
\hline & $\mathrm{I}$ & 45.96 & 71485.56 & 2.35 & 2.70 & 7.32 & 1.87 \\
\hline & $\mathrm{J}$ & 67.28 & 104746.57 & 2.27 & 4.55 & 8 & 2.76 \\
\hline & $\mathrm{K}$ & 11.27 & 8663.19 & 3.54 & 4.55 & 6.9 & 0.9 \\
\hline
\end{tabular}

Now select the indicator data of a provincial power grid company in each region for analysis. According to the principle of the model, the input and output numbers of an area with a comprehensive efficiency of 1 are the most effective use, and the lower the comprehensive efficiency score, the lower its relative efficiency, and there will be at least one input whose target value is not equal to the actual value. The difference between the actual value and the target value is the room for improvement of relatively inefficient unit resources, which can be used as a reference for the adjustment of fixed asset investment. The inputoutput analysis results of each region are as follows:

TABLE III. DEA'S ESTIMATED INPUT-OUTPUT EFFICIENCY IN EACH REGION

\begin{tabular}{|c|c|c|c|c|c|}
\hline Year & DMU & Comprehensive efficiency 1 & Pure technical efficiency & \multicolumn{2}{|c|}{ Scale efficiency } \\
\hline \multirow{11}{*}{2018} & A & 0.768 & 0.907 & 0.847 & irs \\
\hline & B & 0.738 & 0.936 & 0.789 & irs \\
\hline & $\mathrm{C}$ & 1 & 1 & 1 & - \\
\hline & $\mathrm{D}$ & 0.219 & 1 & 0.219 & irs \\
\hline & $\mathrm{E}$ & 0.495 & 0.946 & 0.523 & irs \\
\hline & $\mathrm{F}$ & 1 & 1 & 1 & - \\
\hline & $\mathrm{G}$ & 1 & 1 & 1 & - \\
\hline & $\mathrm{H}$ & 0.474 & 0.877 & 0.540 & irs \\
\hline & I & 0.895 & 1 & 0.895 & irs \\
\hline & $\mathrm{J}$ & 1 & 1 & 1 & - \\
\hline & $\mathrm{K}$ & 1 & 1 & 1 & - \\
\hline
\end{tabular}




\begin{tabular}{|c|c|c|c|c|c|}
\hline Year & DMU & Comprehensive efficiency 1 & Pure technical efficiency & \multicolumn{2}{|c|}{ Scale efficiency } \\
\hline & average value & 0.781 & 0.970 & 0.801 & - \\
\hline \multirow{12}{*}{2019} & A & 0.749 & 0.895 & 0.837 & irs \\
\hline & B & 0.731 & 0.937 & 0.780 & irs \\
\hline & $\mathrm{C}$ & 1 & 1 & 1 & - \\
\hline & $\mathrm{D}$ & 0.220 & 1 & 0.220 & irs \\
\hline & $\mathrm{E}$ & 0.491 & 0.948 & 0.518 & irs \\
\hline & $\mathrm{F}$ & 0.967 & 1 & 0.967 & irs \\
\hline & $\mathrm{G}$ & 1 & 1 & 1 & - \\
\hline & $\mathrm{H}$ & 0.474 & 0.894 & 0.530 & irs \\
\hline & $\mathrm{I}$ & 0.8864 & 1 & 0.864 & irs \\
\hline & $\mathrm{J}$ & 1 & 1 & 1 & - \\
\hline & $\mathrm{K}$ & 1 & 1 & 1 & - \\
\hline & average value & 0.772 & 0.970 & 0.792 & - \\
\hline
\end{tabular}

The input-output effects of each unit are as follows:

In 2018 and 2019, the comprehensive efficiency of C, $\mathrm{G}, \mathrm{J}$, and $\mathrm{K}$ regions is 1 , which is at the forefront of efficiency, indicating that the input and output of the above regions are used most effectively in 2018 and 2019 , And in 2016 and 2017, the comprehensive efficiency of A, $\mathrm{B}, \mathrm{D}, \mathrm{E}, \mathrm{H}, \mathrm{I}$ is not 1 , indicating that there is room for improvement in resource utilization and technology input.

In 2018, the comprehensive technical efficiency of the Mid-F region was 1 , but due to the decline in scale efficiency in mid-2019, the comprehensive efficiency was not 1 and belonged to increasing returns to scale (irs), indicating that its scale needs to increase, thereby increasing scale efficiency and increasing Overall efficiency.

In 2018 and 2019, the pure technical efficiency of A, $\mathrm{B}, \mathrm{D}, \mathrm{E}, \mathrm{H}, \mathrm{I}$ is not 1 , and the scale efficiency is not 1 , and it belongs to increasing returns to scale (irs), indicating that the technology and scale of these regions are not Matching, there may be redundancy in scale investment in these areas. After removing the redundant scale, pure technical efficiency will increase, and overall efficiency will also be improved.

\section{ConClusion}

Based on the precise investment of power grid planning, this paper constructs a real asset input-output evaluation model based on DEA theory, which can effectively understand the current status of input-output benefits in various regions, and can provide a reasonable allocation of investment scale and scientific determination of investment priorities. Data support provides a scientific basis for precision investment, and is of great significance to strengthen the guidance of regional power grid construction, realize precision investment in power grids, promote the scientific, reasonable and orderly development of regional power grids, and enhance power grid development capabilities and enterprise development benefits.

\section{ACKNOWLEDGMENTS}

This study is supported by the Science and technology project of State Grid Zhejiang Electric Power Co., Ltd(5211JY180010).

\section{RefERENCES}

1. Sun Lihui. Innovation of Input-Output Evaluation Method under the New Electric Power Reform [J]. Journal of Anhui Electrical Engineering Professional Technique College, 2020, 25(02): 14-19.

2. Liu Ying, Pan Wei. Research on Investment Strategy Optimization Considering Development Matching Degree and Balance Degree of Distribution Network [J]. Northeast Electric Power Technology, 2020, 41(01): 57-59+62.

3. Zhou Pengcheng, Wu Nannan, Wang Shengyan, Zeng Ming. Design of Input-Output Benefit Evaluation System for Distribution Network Based on Relevance Relation [J]. Sichuan Electric Power Technology, 2019, 42(03): 6-12.

4. Peng Daoxin, Dong Shibo, Wang Ling. Research on Efficiency and Benefit Evaluation System of Power Grid Investment Based on High Quality Development [J]. Construction Economy, 2019, 40(12): 107-114.

5. Zhang Quan, Dai Xianzhong, Han Xinyang, Jin Xiaoling, Zhang Wen, Chen Dan. An Accurate Investment Method of Power Grid Based on Full Life Cycle Input-Output Benefit [J]. Electric Power, 2018, 51(10): 171- 177 . 